\title{
Chapter 9 \\ Where, What and Whom to Study? \\ Principles, Guidelines and Empirical \\ Examples of Case Selection and Sampling \\ in Migration Research
}

\author{
Karolina Barglowski
}

\subsection{Introduction}

Case selection, or sampling-both terms will be used interchangeably throughout this text-denotes the decisions about the research site (where?), the unit of analysis (what?) and participants to a study (who?). Finding answers to these questions is of utmost importance for the production of social scientific knowledge, as it has been underlined early in the social science literature. Glaser and Strauss (1967), have placed the process of selecting cases centrally by developing an own sampling technique ("theoretical sampling"; see Sect. 9.5) as an integral part of their Grounded Theory's research process and methodology. The pivotal role of selecting cases also is mirrored in the title of Ragin and Becker's (1992) famous book "What is a Case? Exploring the Foundations of Social Inquiry". In the last years, in the course of the development and refinement of qualitative methodology, distinct sampling techniques have evolved. Their application depends on the research design and focus as well as the theoretical and methodological approach of the respective study. This chapter aims to provide some guidance for researchers who aim to design a qualitative study on migration, by on the one hand cataloguing selected sampling techniques and on the other hand by discussing their advantages and disadvantages with regards to the distinct field of migration. In doing so, this chapter means to show that researchers need to think carefully about issues of sampling or case selection in qualitative research.

\footnotetext{
K. Barglowski $(\bowtie)$

Technical University Dortmund, Dortmund, Germany

e-mail: karolina.barglowski@tu-dortmund.de
} 
As to the significance of sampling for the validity and generalizability of results, scholars need to reason the rationales of case selection systematically. This point has not always been well reflected in the classic ethnographic studies, where sampling followed rather "opportunistic" (Gobo 2004) considerations, meaning that cases were "given" aspects of the research question (Curtis et al. 2000, p. 1002). Also, studies like William F. Whytes' famous "Street Corner Society" (1943) were interested in the inner workings of a particular "tribe" or a "subculture", thus they usually did not question the boundaries of their empirical field. Nowadays globalized forms of communication, travel and exchange though makes it difficult to say where an empirical phenomenon "ends". Furthermore, as Russell King argues in Chap. 3 of this book, it is the very nature of human migration to traverse spaces and connect two or more places, which often leads to multiple identities and the shift of boundaries in transnational spaces. While the study of the processes through which sociospatial boundaries are drawn has become a central question and topic in contemporary migration research, it is also prone to distinct methodological challenges.

Important challenges for migration research can be derived from the insightful text by Amelina and Faist (2012). In particular the challenges of methodological nationalism and overemphasizing ethnicity need to be reflected in the process of sampling. Methodological nationalism refers to the unquestioned common-sense according to which "nation-state institutions are the main social context within which migration occurs and for which migration is relevant" (Amelina and Faist 2012, p. 1709). When simply assuming that social life takes place within nation state borders, researchers might overlook that many people's lives nowadays take place within transnational social spaces, which arise from the dense and continuous cross-border interactions of various actors (Faist 2009). Selecting cases in various places can be a way to reflect on methodological nationalism ("matched sampling", see Sect. 9.5). Migration research is also challenged when reflecting on the "ethnic lens", meaning a homogenizing view of ethnicity that assumes that people share commonalities because of their assumed and ascribed ethnicity. By overemphasizing ethnicity research risks overlooking that empirical phenomena might be evoked by other boundaries, such as class or gender, which often intersect with ethnicity. For instance, Erel (2002) showed the diversity of childrearing practices, i.e. single motherhood or separation from children, of mothers from Turkey in Germany, which runs counter to stereotyping discourses in Germany about the "traditional" and "patriarch" Turkish family. Such studies let us critically reassess naturalized views on ethnicity and nation. Instead, a transnational lens encourages researchers to question common conflation of nation, ethnicity and sociality and rather to shift attention to "the changes relating to existing boundaries and the formation of new ones" (Faist 2009, p. 70). Sampling is an important way of dealing with such an "ethnic lens", because when interview partners are selected "according to their "ethnicity' or "national belonging'" (Amelina and Faist 2012, p. 1710), there is a risk to also when analysing respondents' accounts to reduce their orientations and practices to their "ethnicity", while, as shown above, they might be evoked by other boundaries. Other ways of sampling, such as selecting respondents according to their legal status (e.g. Nohl et al. 2006), or in a way that they cover respondents 
which are heterogeneous in terms of gender, class and other relevant boundaries (Barglowski et al. 2015) will be discussed later in this chapter.

While the mentioned challenges apply to migration scholarship in general, with regards to the study of migration within the European Union (EU), we need to additionally take into account that we face a unique migration regime. In contrast to most other migration spaces across the globe, where border controls are often rigid practices of facilitation and restriction, inclusion and exclusion, migration of EU-citizens within the EU is not only unrestricted, but is also politically cherished as a means to decrease inequalities and supported by a variety of EU programs. This situation of the freedom of mobility regime of the EU has created new and "liquid" (Engbersen and Snel 2013) patterns of crossing borders, settling, moving on or returning, and also aggravates inequalities between EU citizens and non-EU citizens or between those from the "new" and those from the "old" member states of the European Union. Thus, the study of migration within the EU requires research designs, methods and epistemologies which are able to grasp multiple attachments, mobility opportunities but also "challenges to belonging" (Barglowski 2016) arising from frequent border crossings. At the same time, this particular situation of migration within the EU promises instructive insights into the contingent, and often paradoxical, ways in which the socio-spatial categories of the local, national, transnational and global come to influence contemporary social life.

Given these premises, this chapter seeks to present some guidance for migration researchers in constructing their samples for research. It begins with some notes on the relevance of sampling in qualitative research. Then it generally discusses what "a case" is in qualitative research and as well assesses some guiding principles of case selection. In light of these general thoughts, the subsequent section catalogues different types of case selection, i.e. purposive, theoretical, snowball and matched sampling, and shows their application in selected studies on migration. It ends with an overview of the diverse sampling techniques discussed in this chapter.

\subsection{Some Notes on the Relevance of Sampling}

Researchers' decisions on selecting cases largely depend on what kind of knowledge they intend their study to contribute to. It also depends on whom they want to represent in their study. From the beginning of their research, they need to think about where and from whom they would most likely learn about their particular research objective. For instance, if one is interested in how people come to decide about leaving their home country and moving to another one, one would need to specify what about the many dimensions, people and areas involved in migration decision making is exactly of interest. What is it about people who migrated from a specific area which poses a theoretical or an empirical puzzle? Is it a particular incident, such as the EU enlargement, whose consequences on decision making we want to study? For instance, we could decide that Polish migrants are the most appropriate ones for the latter question, because after Poland's accession to the EU, 
unexpectedly many people emigrated from Poland, particularly to the UK, which makes emigration from Poland a paradigm case for how changing legal and political conditions affect individual behavior (Burrell 2009). So, we could decide to find some Poles which recently arrived in the UK and talk with them about their migration reasons, or about their biographies and family ties and how they were affected by their migration. However, as to the magnitude of Polish migrants in the UK, we would need to decide whom exactly to ask: only those in one particular city, or those with a specific age, social class or family composition? We could decide for a quantitative approach and take a look at an already existing survey, for instance a British household panel, and explore how many Poles are represented there and whether they were asked for their migration reasons. If yes, we could calculate whether there are any correlations between their socio-demographic characteristic such as gender and class, and the reported migration reasons. By this procedure, we would achieve valid results about the composition of mobile populations in a given country and the causal relations between socio-demographic markers and patterns of migration and settlement, which, though, is not the aim of qualitative research. Qualitative research, in contrast, is mostly interested in how actors construct and interpret the world surrounding them, and how these interpretations affect their actions, identities and everyday experiences (see Chap. 7 by Ewa Morawska in this book). Although quantitative and qualitative ways of empirical research are very different as to their epistemologies, methodological foundations and their foci of interest, they share the similarity that, for the most part, they draw their results from a snapshot of the population. Those results heavily depend on what and whom we selected as the object of study and unit of analysis.

In contrast to the random character of case selection in quantitative research, which relies on statistical methods of randomization and probability theory, the selection of cases for qualitative research is much more purposive. In qualitative research, cases always stand for something. No matter how interesting an individual story or biography is, for social scientists it is always a "representative" of some wider pattern. Wider issues that are represented by qualitative research are often experiences, orientations and relationships. An example is the qualitative study by Vullnetari and King (2008) who have explored the experiences of elder people in Albania to cope with the situation when many of their younger generations emigrate from the country and the impacts of such a situation on intergenerational care regimes. Qualitative research also has its strengths in disclosing hidden structures of domination and oppression, such as hierarchies in scientists' transnational mobility (Amelina 2013). Hierarchies and regimes, like other social formations, cannot be studied as a whole. Therefore, researchers need to find some instances which adequately represent the broader phenomenon of interest. In both works we see that sampling refers to at least two general levels: the selection of countries and the selection of participants. In Amelina's work, Ukraine and Germany were chosen because they represent a transnational field of science that connects the "core" and the "periphery" of Europe. She locates her research in the wider area of inequalities in European migration and argues that the enlargement has "created new peripheries of Europe, which include, amongst others, countries such as Russia, Ukraine, 
Belarus and Moldova" (p. 142). For research on inequalities and migration, as she argues, people who move between those countries experience different forms of oppression and exploitation. Thus scientists as a particularly mobile group, and for who mobility is considered an important motor for future careers, are an appropriate group to study. Vullnetari and King (2008) chose Albania as an example of a postcommunist country with high rates of emigration and where elderly care is normatively framed as a family issue. They were interested in how the familial system of care is affected by the mass emigration of young people, who leave their elderly "behind". These decisions show that the selection of sites and people to study depends heavily on the research focus. In a nutshell, constructing cases requires three major steps: first, decisions about the site of study (various places, countries, and different departments), second the unit of analysis (groups, families, values, social classes), and third, the identification of appropriate empirical incidents (situations or interactions to observe, people to ask). These decisions can be taken before starting the research. Or, these decisions about which respondents or incidents to search and to include are conducted simultaneously with the collection and interpretation of data and thus as inseparable research mechanics. Regardless of what kind of sampling we decide to be the most appropriate for our study, the validity and generalizability of results largely depends on our answer to the question of what is this case a case of? It is not enough for a qualitative study to state what is special about a case, but instead we need to clarify which wider social pattern it represents. To start with, the next section will shed light on the not so easy question of what a case is.

\subsection{What Is a Case?}

Ragin and Becker (1992) perfectly summarize the general position about "what a case is" in qualitative social sciences on the cover of their book:

The concept of the 'case' is the basic feature of social science research, and yet many questions about how a case should be defined, how cases should be selected, and what the criteria are for a good case or set of cases are far from settled.

The difficulty of defining and clarifying the concept of a "case" stems from the fact that the definition of a case "depends upon what one is arguing", which means that terms such as countries, units of analysis, sample or population "are definable only by reference to a particular proposition and a corresponding research design" (Gerring 2004, p. 342). When we consider issues that all scholars need to clarify at some point or the other during their research, we get an idea of how complicated decisions of what a case is are. Is a study of emigration rates from Poland a study of many cases (individuals) or one about one case (country)? Is an interview with a Polish migrant woman in Germany about her experiences of migration one about gender specific biographies, one about migrant decision making in general or more specifically about the impact of a political incident (e.g. Poland's accession to EU) 
on migration trajectories? Is it her experiences of settling or how she comes up to live her life transnationally, or the inequalities she encounters? The same interview would eventually be used very differently by researchers with distinct research interests. There might be potential concerns, that when cases are not selected properly, they would not offer the expected results for the specific research interest. That is, however, a minor problem for qualitative researchers, who adjust their research questions and focus during research as a fundamental trait of the explorative stance on the world of qualitative research. Nevertheless, when researchers define what a case for their research is, they need to be aware that they set out the direction of their research results and their generalization. This does not though mean that we need from the beginning know what a case is. Instead, constructing cases can be regarded as one of the goals of qualitative research.

Charles Ragin reports, that during a workshop, Howard S. Becker aimed to motivate researchers to constantly ask themselves "what is my case?" and even more importantly "what is this a case of?" (see Ragin 1992, p. 6). Yet, he also warned them against premature answers, because according to him, the more researchers are unclear about answers to these questions, the more interesting and deep their research is. As such, answers coalesce in the most final stage of research, when results are written up. In consequence, this means that all qualitative researchers need to sustain insecurity during their research and constantly reflect and ask themselves these questions, which for all researchers, and for the less experienced researchers in particular, is tenuous. For dealing with insecurities, some guidelines might be of help. In the following sections, some basic guidelines on the principles of sampling in qualitative research and the most common forms of sampling will be provided, which are illustrated on their use and application in selected migration studies.

\subsection{Principles of Case Selection in Qualitative Research}

The most important feature of sampling in qualitative research is that it needs to be coherent to the research question, methods and research design. There are differences in the sampling strategies, mainly in terms of their foundation in a specific methodological or analytical approach. On the most basic level, the different forms of sampling espouse a "rather pure type of 'theoretical' sampling, designed to generate theory which is 'grounded' in the data, rather than established in advance of the fieldwork, (...) as opposed to those who promote forms of 'purposive' sampling suitable for qualitative research which is informed a priori by an existing body of social theory on which research questions may be based." (Curtis et al. 2000, p. 1002). Despite methodological differences, all qualitative methods share some basic principles. They are all oriented toward an exploration of the diversity of human life in an inductive rather than a deductive manner. Also, they share the objective of refining or even developing theories. Therefore, we can list some key features of sampling in qualitative research: 
1. Samples must not be drawn in a probabilistic or statistic manner, but on purposive or theoretical considerations.

2. Samples are usually not wholly pre-specified, but either there are some general criteria established before research (see later on purposive sample) or the selection is conducted in a circular process of data collection and analysis and identification of further relevant cases (see later on theoretical, snowball and matched sampling). Sampling is either driven by the "theoretical framework, which underpins the research question from the outset or by an evolving theory which is derived inductively from the data as the research proceeds" (Curtis et al. 2000, p. 1002).

3. Qualitative research should be reflexive and transparent about the principles of selecting cases, because they largely influence which results we gain and how we can generalize them. The research thus needs to be transparent about why and which cases were selected and often also about which cases were deliberately not considered.

4. Samples are small, but analyzed extensively. Each case provides typically a large amount of information.

5. The sample should enable analytic generalizations, which are either oriented toward constructing a typology or toward generic processes. In contrast to statistical generalization, this type of generalization does not generate results which can be applied to wider populations, but offers new insights into existing theories or helps to elaborate or reformulate existing theories (Curtis et al. 2000).

\subsubsection{Sample Size and Saturation}

As one part of sampling, the sample size has attracted some attention recently. Literature agrees that the sample size largely depends on the approach to qualitative inquiry pursued by the researcher. The discussion of numbers of cases stems from a more quantitative logic where generalization happens based on the statistical representation of the population, which requires a large sample. It is thus not the size of the sample that is relevant for the quality of the results, but much more that it covers the diversity and differences in the empirical field, which usually happens through comparisons and contrasts. When one is interested in the experiences of migrant women who come to Germany and the inequalities they encounter when having their degrees recognized, one would probably need two contrasting cases, a woman who encounters some problems and another one who does not. However, contrasts can also be built based on the literature, theoretical considerations or document analysis. In this way, one case can provide valid results when it is analyzed as to its deep structures and contrasted with what is known about the field or generative mechanisms discussed in the literature. 
According to Grounded Theory Methodology, the sample size is large enough when the results are saturated (Corbin and Strauss 1990; Glaser and Strauss 1967). Saturation means that further data collection would not provide relevant results to the themes, concepts, codes or theory. In other words, we search for cases as the research proceeds and we stop sampling when we find no deviant cases anymore. This quality criterion might sound logical and yet meeting it poses some challenges for experienced and less experienced researchers alike. First of all, there is limited practical guidance for researchers to assess whether their sample is saturated which resonates with a lack of transparency in most research articles on how researchers came to detect their sample as saturated (O'Reilly and Parker 2012). Furthermore, it is debatable whether saturation is a general quality criterion for qualitative research or only for samples obtained by theoretical sampling in Grounded Theory based studies. One could also doubt whether there can be a situation in the empirical world where more data would not offer more information.

Although the sample size is not a very reliable characteristic for the quality of findings, we are very often confronted with having to provide a definite sample size, for instance when writing exposes for thesis or research proposals for funding. Here, it is important to be aware of the reader of the proposal. While qualitatively trained readers will most probably know that size is not the most relevant predictor for the quality of the research and findings, many social scientists until now equate size with quality. Therefore, some studies provide recommendations for sample size, which can serve as a straightforward example of how many cases to put into our proposal as well as a legitimation for why we have decided for a particular number. For instance, Guetterman (2015), based on a review of peer-reviewed research, and Mason (2010), based on a review of $\mathrm{PhD}$ studies, provide definite numbers for respective methodologies, which range from 20 to 30 in Grounded Theory Methodology to three to ten cases in ethnography.

\subsubsection{Generalization of Results}

Sampling is crucial for the generalization of research results. In contrast to quantitative research, the aim of qualitative research is not to test a theory, but to reexamine existing theories or generate new ones. Generalization in qualitative research denotes the process through which scholars infer regularities in the social world from mostly consciously chosen cases. Therefore, the sample should not match the criteria of statistical representativeness, but of "social representativeness", which means to identify the general patterns or types represented by cases (Gobo 2004, p. 423). Yet, in inferring broader patterns from singular instances, the interpretivist stance on the world is faced with an inherent conflict. The strength of qualitative research is at the same time its weakness: its focus on time-and context specific ways of lives, subjective meanings and identity constructions means that it is critically engaged with "groupism", meaning the equation of structural characteristics 
with respective subjectivities, meanings and action (see Brubaker 2004). At the same time, when being too close to the singular case and its uniqueness, such analysis runs the risk of being haphazard. Furthermore, it might misspend the opportunity of the real strength of qualitative research, which is to bring hidden structures of social life to the fore. Therefore, researchers need to be cautious when more generally asserting about what was learned from singular cases. On the one hand, the uniqueness, time and context specificity of cases needs to be shown while, on the other hand, these need to be related to more general patterns. Constant reflections of one's own position and own knowledge on the empirical field, as well as on the whole process of analytical generalizations is essential to qualitative research.

Besides inferring patterns from cases, typologies, in the tradition of Weberian "ideal types" are a common way of generalizing qualitative research results. Constructing typologies always involves overemphasizing similarities among people classified as one "type", while, at the same time, underemphasizing similarities between "types". For instance, Pustułka (2016) has studied different types of mothering among Polish migrants in Germany and the UK. The author has used a sampling strategy which aimed to depict the heterogeneity among Polish migrant women in terms of their ethnic, class and gender identities by using a "nonprobabilistic and deliberative sampling strategy" (p. 45). With such a sample, the author organized her findings around three types of mothering, "each one confronted with the explicative terms related to various gender and ethnic identifications expressed and desired by Polish migrant women" (p. 48).

\subsection{Sampling Strategies and Their Application in Migration Research}

This section portrays different sampling strategies and exemplifies their application in selected migration studies. The different strategies enable the construction of and approach to a variety of research units. They have particular strengths and weaknesses for dealing with the aforementioned methodological challenges in migration research and thus their choice is dependent on the research focus.

\subsubsection{Theoretical Sampling}

Theoretical sampling is one component of the Grounded Theory Methodology and involves that the research units are not defined before the research, but are selected during the process, based on analytical considerations of the information needed and aims to achieve a relevant sample. The pioneers of Grounded Theory research, Barney Glaser and Anselm Strauss, developed theoretical sampling during their 
research in medical sociology in the 1960s. They describe in the following passage how they proceeded in theoretical sampling:

\begin{abstract}
Visits to the various medical services were scheduled as follows. I wished first to look at services that minimized patient awareness (and so first looked at a premature baby service and then at a neurosurgical service where patients were frequently comatose). Next I wished to look at the dying in a situation where expectancy of staff and often of patients was great and dying was quick, so I observed on an Intensive Care Unit. Then I wished to observe on a service where staff expectations of terminality were great but where the patient's might or might not be, and where dying tended to be slow. So I looked next at a cancer service. I wished then to look at conditions where death was unexpected and rapid, and so looked at an emergency service. While we were looking at some different types of services, we also observed the above types of services at other types of hospitals. So our scheduling of types of service was directed by a general conceptual scheme-which included hypotheses about awareness, expectedness, and rate of dying-as well as by a developing conceptual structure including matters not at first envisioned. Sometimes we returned to services after the initial two or three or four weeks of continuous observation, in order to check upon items which needed checking or had been missed in the initial period. (Glaser and Strauss 1967, p. 59)
\end{abstract}

This quote is instructive, as it shows the iterative process of sampling guided by experiences and reflections during research. Theoretical sampling is a very common method of contemporary social science research, also in migration studies. Its main premise is the search for contrasting cases which can be used to enhance the knowledge about the topic of interest, as well as to gather its multi-dimensionality and complexity. This method is also appropriate when researcher's knowledge on the field is limited, or when the focus of the research is very abstract and hard to break down. For instance, Richter (2012) has found that her research focus on the formation of transnational social spaces between Spain and Switzerland is far too abstract as to use snowball-sampling and to ask people about others they know who are "transnational". Furthermore, as her research was interested in how people conceive of transnational social spaces, she felt that she would have influenced her respondents too much while interviewing when it would be known that she searches for "transnationals". Thus, she opted for theoretical sampling, which she used in the following way:

As a first step, I started with a sample of 19 second-generation Spaniards in Switzerland. The sample aimed at a maximum variety in order to draw a first picture of the ways in which people of the second generation maintain or abandon transnational relationships. It followed the logic of theoretical sampling, diversifying the sample finally along categories such as gender, age, educational level, professional status, and parents' region of origin in Spain. This first phase served to initiate the research and the research relationship with the interviewees. Biographical interviews gave good insight into people's connections to Spain, the people in their networks, and site attachment. Based on these first insights, I was able to make a selection of the cases to follow further. I compared the interview focusing on the way they maintained their transnational linkages. The temporal aspect proved to be an important characteristic when describing the way the second generation inherited the networks from their parents, appropriated them, and maintained them (Richter 2012, p. 17). 
Theoretical sampling is a very appropriate sampling strategy for migration research, as it allows to deconstruct the "ethnic lens" when searching for contrasting cases. In this way, other categories than ethnicity, such as in Richters' study "temporal aspects" can come to the fore. Theoretical sampling thus meets the main strengths of qualitative research, which is the exploration of concepts from empirical data in an inductive manner, thereby extending, refining or even building theories. At the same time, this sampling can be costly and time-consuming. Furthermore, as to its cyclical nature, it can be hard to apply it in the "textbook-way" to the realities of social scientific research, which usually follows a more linear way of sampling, collecting, analysing and writing up.

\title{
9.5.2 Snowball Sampling
}

Snowball sampling is another technique where the sample evolves during research. It basically proceeds in that the researcher identifies one or more respondents and, after interviewing them, asks them for further contacts to their relatives or friends. As such, snowball sampling allows the tracing of networks and relationships. Akanle (2013), for instance, describes the merits of the snowball sampling technique he used in his study on Nigerian migrant networks, when he describes how he recruited participants to his study:

\begin{abstract}
A snowball technique was employed in the selection of respondents. This method consisted of identifying and contacting respondents who were then used to refer the researcher to other respondents who were relevant, available and willing to participate in the study. Inclusion however, depended on respondents' consent to be interviewed. The snowballing technique was particularly useful because a lot of the potential respondents were skeptical of the researchers' intentions. Initial respondents and contacts were thus relied upon of recommendations to further respondents. Hence, as an advantage of this technique, the snowballing technique was found to be suitable, as the respondents were involved in various kinds of networks or relationships with other potential respondents who shared the characteristics of interest (Akanle 2013, p. 57).
\end{abstract}

For migration research, this sampling technique allows to reflect on some of the methodological challenges. When people are recruited based on their relation to other respondents, researchers might come in contact with people who live outside the country of where the research has started. Also, researchers might find people within one network who are of multiple national and ethnic belonging, thus fighting the "ethnic lens". However, if only snowball sampling is used, and if the studies' focus is not an analysis of networks or relationships, this sampling might fail to reach those units of analysis, which are not connected to the units of entry. Multiple entry points can decrease the risk of being limited to one network as a research unit. 


\subsubsection{Matched Sampling}

The transnational perspective aims to explore and understand the multi-local positioning and flows of people, networks, goods, and organizations. In order to capture these complexities, transnational research in particular requires a sampling strategy, which allows going beyond the national frame of reference. A convenient sampling strategy was developed by Mazzucato (2009). In her research, she was interested in how flows of goods, money, services, and ideas between Ghanaian migrants in the Netherlands and people they know in their home country transform the institutions that shape local economies both at home and abroad. Her research is based on the assumption that through contemporary means of communication and travel people can be engaged in various places at the same time. Mazzucato (2009) implemented this notion methodologically in a matched sample design:

First, the unit of analysis is a network of people who are not necessarily based in the same nation-state. Rather than an individual migrant or her household back home as was typical of migration studies of the past, here the unit of analysis includes the migrant but also her friends, family, colleagues and others with whom she engages in trans-border exchanges. This makes the unit of analysis the transnational network. Second, simultaneity is taken into account by conducting the study through a team of researchers based in the main locations of migrants' networks so as to study the people in a network at the same time (Mazzucato 2009, p. 219).

This sampling is mostly a network-based approach, which is a common optic in contemporary migration research. It is convenient in that it allows reflecting on methodological nationalism and the ethnic lens. However, when the research focus is broader than the relations between migrants and their relatives other techniques of sampling need to be applied. Furthermore, methodological ambitions often have their challenges. For instance, obtaining contact details in a matched sample design might be demanding because people may be doubtful about giving out contact details of their significant others in the emigration countries, especially when transnational research teams are involved in the project, as the interviewers in the immigration and emigration countries are often not the same person. Interviewees might also hesitate to give the contact details of their friends and relatives who they identified as "vulnerable". This sampling method thus proves to be challenging and can lead to dissatisfaction during the research (Barglowski et al. 2015).

\subsubsection{Purposive Sampling}

Purposive sampling is useful when the research is orientated towards a rather clearcut research interest. In the literature, it is also known as "opportunistic", "maximum variation", "typical case", "homogenous", "theory based", "random/stratified purposeful", "deliberate" or "convenience" sampling (Iosifides 2011). It involves the identification of relevant cases before the research is conducted. There are 
different strategies of constructing a purposive sample. Patton (1990) is usually the authority when it comes to delineating the basics of purposeful sampling:

The logic and power of purposeful sampling lies in selecting information-rich cases for study in depth. Information-rich cases are those from which one can learn a great deal about issues of central importance to the purpose of the research, thus the term purposeful sampling. For example, if the purpose of an evaluation is to increase the effectiveness of a program in reaching lower-socioeconomic groups, one may learn a great deal more by focusing in depth on understanding the needs, interests, and incentives of a small number of carefully selected poor families than by gathering standardized information from a large, statistically representative sample of the whole program. The purpose of purposeful sampling is to select information-rich cases whose study will illuminate the questions under study (Patton 1990, p. 169).

What is considered to be an "information-rich case" can either be identified based on own knowledge about the field, mirror the research interest, or be derived from theoretical considerations. A purposive sampling may make it easier when writing proposals demands to provide a definite sample size, than with the more cyclical forms of theoretical or snowball sampling, where the sample evolves throughout the research. Purposive sampling is useful when the research is orientated towards a specific case and when researchers have a rather clear image of what they aim to find out. For instance, in a joint research project on migrants' self-entrepreneurship, cases were deliberately chosen as to rather clear characteristics:

[The] central cases were male and female migrants and native-born females who, due to dismissal, operational termination or a longer period of family life, no longer had reasonable chances for a profitable future in similar employment situations. Further study participants were female members of the dominant society and relatives and offspring of first- and second-generation migrants who, despite completing educational and training programsin many cases a university degree-for an occupation for which they were well qualified, were not able to attain traditional dependent vocational placements. They had opened, either with or without the support of private commercial assistance programs, small businesses which typically offered personalized services or had started a so-called solo selfemployment business which relied solely on the diligence of the owner him/herself. In the first years, incomes of such activities seldom reached levels considerably higher than those of unemployment and social assistance, and in some cases were even lower. Extensive expansion in the future was not expected (Apitzsch 2003, pp. 165-166).

Alternatively, the purposive sample method can also be used when the research design allows only to have limited numbers of cases as data sources. This kind of sampling can also be used in multi-sited research designs, where data are collected in different locales. In migration research, multi-sited mostly means field work in different countries. Vullnetari and King (2008) were interested in how care for elderly works in countries with high levels and normative ideals of familial care, but simultaneously very high rates of emigration of young people. First, they have picked migration from Albania because "the collapse of the old regimes' paternalistic welfare state has combined with the mass emigration of working-age people to produce a new social phenomenon of abandoned and destitute elderly" (pp. 139140). They have decided to study the mass emigration to Greece, as a main destination country for Albanians, and have decided for a multi-sited approach, and 
conducted interviews with different types of respondents in different places. Within these "country" cases, these authors picked cases, such as people to ask or situations to observe, that would most likely be good "informants":

\begin{abstract}
Interviews $(\mathrm{n}=38)$ in a cluster of four small villages in southeast Albania. All interviewees were selected as older village residents with adult children currently living abroad. Some of the households also had children who had migrated internally to Tirana or other important towns.

Interviews $(\mathrm{n}=23)$ with Albanian migrants from the four villages who had relocated to the Greek city of Thessaloniki. Some of these were family members of interviewees in the villages. In Thessaloniki our focus was both on the care practices of migrants towards their elderly relatives back home, and on older people who had followed their children to Greece (Vullnetari and King 2008, p. 148).
\end{abstract}

Another purposive way of constructing samples is according to analytical considerations. This type of sampling does not involve "information-rich" case, but the construction of status groups, as associations between respondents' characteristics. A very illustrative example for such a sample was provided in Nohl et al. (2006). The authors sampled respondents according to their legal status, thereby aiming to avoid an ethnic lens. At the same time, collecting accounts from respondents with different legal status allowed for thorough comparisons of the impact of legal status on, in their case, migrants' labor market incorporation. Comparisons in many qualitative methodologies are an important analytical procedure to achieve valid results, for instance in Grounded Theory Methodology. That is, because rather than the size of the sample, the internal variation is an important quality criterion of qualitative studies. In their study on cultural capital in migration, the authors defined different groups of migrants and investigated how they can "transport" their cultural capital from one country to the other. As such, the investigation's objective was to analyze the processes of capital recognition, such as skills and knowledge in different national contexts. Their sampling perfectly matched their research question, as the main aim was to find out how different status groups, in terms of educational credentials and where they were obtained, matter for the opportunities and restrictions various "groups" face in entering the labor markets in the immigration country.

[I]n particular we differentiate between persons with medium and high educational qualifications, between so-called Bildungsinländer (the group of indigenously trained persons whose last educational title was acquired after migrating) and Bildungsausländer (the group of foreign trained persons whose last educational title was acquired before migrating). Furthermore, we categorize groups with respect to their right of residence and legal access to the labor market. Formal legal equality means in this context that migrants have no legal problems with respect to their right of residence and work permit which would put them into a position of disadvantage compared to the native-born population (Nohl et al. 2006, p. 31).

Researchers, however, need to be aware that by having many considerations prior to entering the field, they might exclude empirical evidence besides these categories. Furthermore, this type of case selection might reproduce "groupism", in terms of treating scientific categories as natural categories and assume equal identifications 
within those groups. The cited authors here are well aware of the potential limitations of their sampling strategy, which, as all types of sampling, faces particular challenges. Nohl and colleagues reflect groupism and the reification of ethnonational categories by constructing their sampling according to legal groups and not ethnicity.

\subsection{Conclusion}

This chapter discussed the basic principles and guidelines of sampling in qualitative research and emphasized the significance of selecting cases for the generalization and validity of findings. Therefore, when designing a qualitative study, researchers need to carefully think about which sampling strategy to use, because the way they select their cases largely influences the breadth and depth of their study. The purposive character of sampling in qualitative research urges researchers to constantly reflect on the question of what general pattern their sample will represent, or in other words: what is the case a case of? Searching answers to this question is an inherent part of the qualitative research process. It can be demanding as it requires researchers to deal with insecurities of not knowing where exactly their research will lead them. At the same time, the field of migration involves some particular considerations for case selection, because of the methodological challenges that migration research is confronted with: most importantly methodological nationalism and the ethnic lens (Amelina and Faist 2012). Notably in research on migration within the European Union, where its freedom of mobility regime yields multiple border crossings, research techniques need to be open to the various socio-spatial boundaries that come to influence contemporary social life. Accordingly, researchers should avoid the common-sense that nation states and ethnicity are the main organizing principles of sociality. Sampling is a crucial part of research which enables interrogating the significance of the boundaries of nation states and ethnicity. To provide some guidance, this chapter discussed the basic principles, merits and disadvantages in relation to these challenges of the most common sampling techniques in migration research:

1. Theoretical Sampling: this sampling is based on the inductive method of Grounded Theory Methodology. Its merits are that it evolves during the research process and thus corresponds with the explorative character of interpretative research. Also, as to its comparative approach and goal of maximum variation it can reduce overemphasizing ethnicity. Yet, it is often hard to implement, because it is time consuming and the quality criterion of saturation for samples, which means that more data would not lead to more information, makes it hard to offer definite sample sizes in writing research proposals as well as it maximizes insecurities in the research process. 
2. Snowball Sampling: this sampling allows tracing networks and relationships by asking respondents for contacts to people they know. It is a very convenient method to analyse networks, but it minimizes the probability of accessing people which are not connected to the units of entry and if not well reflected it might be prone to an "ethnic lens". Multiple entry points can decrease the risk of being limited to one network as a research unit.

3. Matched Sampling: this convenient sampling strategy was put forward by Mazzucato (2009). It is based on the assumption that people are simultaneously positioned in more than one place and thus involves data collection in different places. It is particularly fruitful for transnational research and dealing with methodological nationalism, though it runs the risk of an ethnic lens if not carefully implemented. Also, it can be costly and time-consuming as well as it proved to be hard to reach respondents in the emigration countries, particularly those which were perceived by their relatives as "vulnerable" (Barglowski et al. 2015).

4. Purposive Sampling: this sampling relies on researcher's judgment to select participants with diverse characteristics. In contrast to the other sampling techniques, the characteristics of respondents are established before entering the field. This makes it easier for writing those research proposals where definite information, such as numbers, of respondents need to be stated as well as it might provide some security towards the contingencies of the research process. But it also runs the risk of the "ethnic lens", as well as of not reaching cases outside the pre-established categories. Its potential to avoid methodological nationalism depends on the application during the research.

\section{References}

Akanle, O. (2013). Kinship networks and international migration in Nigeria. Newcastle upon Tyne: Cambridge Scholars Publishing.

Amelina, A. (2013). Hierarchies and categorical power in cross-border science: Analysing scientists' transnational mobility between Ukraine and Germany. Southeast European and Black Sea Studies, 13(2), 141-155. https://doi.org/10.1080/14683857.2013.789670.

Amelina, A., \& Faist, T. (2012). De-naturalizing the national in research method-ologies: Key concepts of transnational studies in migration. Ethnic and Racial Studies, 35(10), 1707-1724. https://doi.org/10.1080/01419870.2012.659273.

Apitzsch, U. (2003). Gaining autonomy in self-employment processes. The biographical embeddedness of women's and migrants' business. International Review of Sociology, 13(1), 163182. https://doi.org/10.1080/0390670032000087041.

Barglowski, K. (2016). Migration pressures and opportunities: Challenges to belonging within the European Unions' mobility regime. InterDisciplines-Journal of History and Sociology, 7(1), 63-68. https://doi.org/10.2390/indi-v7-i1-153.

Barglowski, K., Bilecen, B., \& Amelina, A. (2015). Approaching transnational social protection: Methodological challenges and empirical applications. Population, Space and Place, 21(3), 215-226. https://doi.org/10.1002/psp.1935.

Brubaker, R. (2004). Ethnicity without Groups. Cambridge, MA: Harvard University Press. 
Burrell, K. (Ed.). (2009). Polish migration to the UK in the 'new' European Union: After 2004. Burlington: Ashgate.

Corbin, J., \& Strauss, A. (1990). Grounded theory research: Procedures, canons, and evaluative criteria. Qualitative Sociology, 13(1), 3-21. https://doi.org/10.1007/BF00988593.

Curtis, S., Gesler, W., Smith, G., \& Washburn, S. (2000). Approaches to sampling and case selection in qualitative research: Examples in the geography of health. Social Science and Medicine, 50(7-8), 1001-1014. https://doi.org/10.1016/S0277-9536(99)00350-0.

Engbersen, G., \& Snel, E. (2013). Liquid migration: Dynamic and fluid patterns of post-accession migration flows. In B. Glorius, I. Grabowska-Lusinska, \& A. Kuvik (Eds.), Mobility in transition: Migration patterns after EU enlargement (pp. 21-40). Amsterdam: Amsterdam University Press.

Erel, U. (2002). Reconceptualizing motherhood: Experiences of migrant women from Turkey living in Germany. In D. F. Bryceson \& U. Vuorela (Eds.), The transnational family: New European frontiers and global networks (pp. 127-146). Oxford: Berg.

Faist, T. (2009). Making and remaking the transnational: Of boundaries, social spaces and social mechanisms. Spectrum: Journal of Global Studies, 1(2), 66-88.

Gerring, J. (2004). What is a case study and what is it good for? American Political Science Review, 98(2), 341-354. https://doi.org/10.1017/S0003055404001182.

Glaser, B. G., \& Strauss, A. L. (1967). The discovery of grounded theory: Strategies for qualitative research. Chicago: Aldine.

Gobo, G. (2004). Sampling, representativeness and generalizability. In C. Seale, G. Gobo, J. F. Gubrium, \& D. Silverman (Eds.), Qualitative research practice (pp. 405-426). London: SAGE.

Guetterman, T. C. (2015). Descriptions of sampling practices within five approaches to qualitative research in education and the health sciences. Forum: Qualitative Social Research, 16(2). http://nbn-resolving.de/urn:nbn:de:0114-fqs1502256

Iosifides, T. (2011). Qualitative methods in migration studies: A critical realist perspective. Farnham: Ashgate.

King, R. (2018) Context-based qualitative research and multi-sited migration studies in Europe. In R. Zapata Barrero \& E. Yalaz (Eds.), Qualitative research in European migration studies (pp. 52-79). Cham: SpringerOpen.

Mason, M. (2010). Sample size and saturation in $\mathrm{PhD}$ studies using qualitative interviews. Forum: Qualitative Social Research, 11(3), 8. http://nbn-resolving.de/urn:nbn:de:0114-fqs100387

Mazzucato, V. (2009). Bridging boundaries with a transnational research approach: A simultaneous matched sample methodology. In M.-A. Falzon (Ed.), Multi-sited ethnography: Theory, praxis and locality in contemporary research (pp. 215-232). Aldershot: Ashgate.

Morawska, E. (2018). Qualitative migration research: Goals pursued, questions asked, and answers accommodated. In R. Zapata Barrero \& E. Yalaz (Eds.), Qualitative research in European migration studies (pp. 153-178). Cham: SpringerOpen.

Nohl, A.-M., Schittenhelm, K., Schmidtke, O., \& Weiss, A. (2006). Cultural capital during migration-A multi-level approach to the empirical analysis of labor market integration amongst highly skilled migrants. Forum: Qualitative Social Research, 7(3), Art. 14. http://nbn-resolving. de/urn:nbn:de:0114-fqs0603143

O'Reilly, M., \& Parker, N. (2012). "Unsatisfactory saturation": A critical exploration of the notion of saturated sample sizes in qualitative research. Qualitative Research, 13(2), 190-197. https:// doi.org/10.1177/1468794112446106.

Patton, M. Q. (1990). Qualitative evaluation and research methods. Beverly Hills: SAGE.

Pustułka, P. (2016). Ethnic, gender and class identities of Polish migrant mothers: Intersecting maternal narratives with transnationalism and integration. Social Identities, 22(1), 44-61. https://doi.org/10.1080/13504630.2015.1110357.

Ragin, C.C. (1992). Introduction: Cases of "What is a case?". In. C.C. Ragin \& H.S. Becker, H. S. (eds.). What is a case?: Exploring the foundations of social inquiry. Cambridge: Cambridge University Press, pp. 1-17. 
Richter, M. (2012). Researching transnational social spaces: A qualitative study of the Spanish second generation in Switzerland. Forum: Qualitative Social Research, 13(3), Art. 8. http:// nbn-resolving.de/urn:nbn:de:0114-fqs120385

Vullnetari, J., \& King, R. (2008). “Does your granny eat grass?” On mass migration, care drain and the fate of older people in rural Albania. Global Networks, 8(2), 139-171.

Whyte, W. F. (1943). Street corner society: The social structure of an Italian slum. Chicago: University of Chicago Press.

Open Access This chapter is licensed under the terms of the Creative Commons Attribution 4.0 International License (http://creativecommons.org/licenses/by/4.0/), which permits use, sharing, adaptation, distribution and reproduction in any medium or format, as long as you give appropriate credit to the original author(s) and the source, provide a link to the Creative Commons license and indicate if changes were made.

The images or other third party material in this chapter are included in the chapter's Creative Commons license, unless indicated otherwise in a credit line to the material. If material is not included in the chapter's Creative Commons license and your intended use is not permitted by statutory regulation or exceeds the permitted use, you will need to obtain permission directly from the copyright holder.

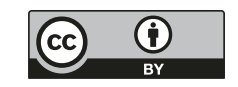

